\title{
Resenha de Lyric in the renaissance, de Ullich Langer
}

Marcus De Martini

Universidade Federal de Santa Maria

Andrio J. R. dos Santos

Universidade Federal de Santa Maria

LANGER, Ullrich. Lyric in the Renaissance: From Petrarch to Montaigne. Cambridge, UK: Cambridge University Press, 2015, 224p.

Ainda sem tradução no Brasil, Lyric in the Renaissance: From Petrarch to Montaigne (2015), de Ullrich Langer, tem como objetivo investigar o efeito da poesia lírica no Renascimento e já se estabeleceu como uma das obras mais importantes sobre o tema lançadas nos últimos anos, tema a respeito do qual, vale ressaltar, muito já se escreveu.

De acordo com Langer, a lírica teria um efeito peculiar, por ele denominado de "singular lírico", que seria justamente o caráter distintivo do gênero convencionalmente tratado como lírico. O autor desenvolve seu estudo em cinco capítulos, cada um objetivando analisar a "singularidade", como caráter distintivo, na obra de um dado poeta. Respectivamente, Langer examina as obras de Petrarca, Charles d'Orléans, Ronsard, Du Bellay e Montaigne.

Nessa discussão, o autor leva em conta diversos problemas acerca da concepção teórica de gênero lírico, como a questão da subjetividade e da própria compreensão genérica de lírica. Langer menciona que a subjetividade tornou-se relevante para a discussão da lírica como gênero, embora os termos em que essa discussão se estabeleça tenham pouco a ver com a noção moderna de subjetividade, caracterizada pelo autor como a expressão de um "eu" íntimo. Para Langer, a lírica da pré-modernidade (early modern) caracteriza-se por uma variedade de processos articulados pela linguagem, cuja base seria retórica. Dessa forma, a subjetividade se estabelece como um dos mecanismos da lírica, não como aquilo que a define.

No tocante ao problema no gênero, vale destacar que, na Grécia arcaica, a lírica era compreendida como um tipo de composição oral, acompanhada por lira ou cítara, que possuía função social e caráter coletivo. Contudo, devido à falta de uma definição, principalmente porque Aristó- 
Marcus De

Martini

Andrio J. R. dos

Santos

216

teles, em sua Poética, pouco menciona a seu respeito, o termo "lírico" se tornou algo aglutinador, abrangendo tudo o que não é épico, trágico ou cômico. Embora Langer não procure conceber uma noção de gênero lírico, uma vez que intenta discutir as características da lírica a partir de seu efeito, o autor defende que a distinção entre a poesia grega arcaica e a "lírica" não está necessariamente calcada no caráter escrito das coleções líricas, surgidas a partir do helenismo, ainda que esse seja um fator determinante. Para o autor, existe um tipo de "modernidade" no período pré-moderno, estabelecida como um tipo de plano de fundo, que possibilita a distinção entre a poesia arcaica grega e a poesia Antiga, escrita. A característica distintiva, possibilitada por esse background, manifesta-se como uma "singularidade lírica", surgida principalmente depois de Petrarca. Uma das marcas dessa característica seria uma "intensidade singular", perpassada por um caráter subjetivo. Na perspectiva de Langer, a verificação dessa singularidade opera uma mudança no caráter da lírica, demonstrando sua capacidade de designar distintas formas de particularização humana. Dessa forma, a questão da "singularidade" provoca profundas implicações na noção de poesia pré-moderna, uma vez que se estabelece de forma indissociável do efeito causado pela poesia lírica, não mais coletivo, e, sim, particularizante.

Por sua vez, a "intensidade singular", perpassada por um caráter subjetivo, seria composta por diversas instâncias, que podem abarcar a expressão de um "eu" particular, a enunciação de um sujeito, a expressão da experiência individual ou diversas manifestações da figura do poeta. No entanto, essa intensidade, ressalta Langer, pode ser integrada por todas essas instâncias ou apenas algumas delas. Isto porque a "intensidade singular", assim com a subjetividade, seria um efeito ou mecanismo retórico. Como exemplo, Langer menciona que um dos aspectos mais estudados da obra de Petrarca é a noção de um "eu" constituído por características como, por exemplo, a solidão, uma consciência histórica e/ou a intimidade epistolar. Este seria um fator definidor do efeito da lírica, determinado por seu caráter negativo: "a delineation, an exclusive pointing, a paring-down, a redundancy, a contrasting. Their nature becomes clearer when we consider the starting point for early modern conceptions of 'literary' communication, which is rhetoric" (LANGER, 2015, p. 23).

O caráter subjetivo, na perspectiva do autor, se estabelece a partir de um plano de fundo retórico. A poesia estaria indissociavelmente ancorada em uma cultura retórica, que permeia todos os níveis de uma sociedade letrada. Nessa perspectiva, todo discurso escrito ou oral 
funcionaria como uma conexão entre os membros de uma coletividade política. A retórica, nesse caso, seria a sistematização desse processo. Desse modo, o discurso, mesmo quando particular, emergiria de um senso de comunidade, de uma perspectiva social que, segundo Langer, é perpassada por um grau "subjetivo".

Tendo isso em vista, o autor discute o efeito da lírica, assim como seu caráter distintivo, a partir da noção de "singularidade lírica". Em sua argumentação, Langer analisa a obra de Petrarca, Charles d'Orléans, Ronsard, Du Bellay e Montaigne, em uma discussão organizada em cinco capítulos, cujo objetivo é compreender de que forma a "singularidade" se manifesta na obra e no contexto específicos dos referidos autores, considerando suas principais características.

No capítulo dois, logo após a introdução, Langer trata da obra Resenhade Lyric in the renaissance, de Ullrich Langer de Petrarca. A "singularidade", no referido poeta, seria definida por figuras redutivas, como uma gradação que encapsula algo em um momento ou indivíduo específico. Em um dos exemplos citados por Langer, poema 61, Petrarca definiria o momento exato em que foi arrebatado pelos olhos de sua amada, Laura: "fui giunto/ da' duo begli occhi che legato m'ànno" (quando fui arrebatado por adoráveis olhos que me dominaram). Através desse momento, concernente ao olhar, opera-se um efeito a partir do qual a realidade desse "eu" muda. Esse efeito, segundo Langer, também é atingido através de redundância semântica, cuja função seria destacar pontos do texto através da repetição de outros. Essas características, em Petrarca, geram um sentido de exclusividade, de particularidade insubstituível e não permutável, que seria sua forma de "singularidade lírica", estabelecida em caráter existencial.

No capitulo três, Langer analisa a obra de Charles d'Orléans. Diferentemente de Petrarca, a singularidade na obra do referido poeta não se caracteriza pela busca do outro ou de um instante relativo ao outro, mas, sim, pela expressão de um "eu", compreendido como um particular apartado do mundo, como um objeto perdido. Em um dos exemplos citados por Langer, Balada 63, um homem adentra na floresta da tristeza, então surge diante dele a deusa do amor, questionando-o aonde ia. Eis que ele responde: “Et qu'a bon droit appeller me povoye/L'omme esgaré qui ne scet ou il va" (Com todo direito eu me consideraria um homem perdido, que não sabe para onde vai). De acordo com Langer, a sugestão de exílio, a sensação de estar apartado do mundo e dos seres seria a "singularidade existencial" de d'Orléans, definida a partir de sua melancolia. 
Marcus De

Martini

Andrio J. R. dos

Santos

No capítulo quatro, Langer trata da obra de Ronsard, que considera um herdeiro de Petrarca. Contudo, ao invés de apresentar características devedoras deste, Ronsard introduz reciprocidade erótica como uma intenção da lírica. Um dos exemplos apresentados por Langer é o poema Les Amours et Les Folastries, que apresenta Cassandra, amada do poeta, recolhendo flores em um bosque. No poema, as flores respondem ao seu toque, em uma metáfora erótica: “voici la prée verdelette,/ Qui prend vigueur de sa main la touchant" (aqui está a pradaria verde que ganha vigor ao toque de sua mão). Desse modo, Langer defende que a "singularidade" presente na obra de Ronsard se estabelece a partir da representação de erotismo e de reciprocidade amorosa.

No capítulo cinco, Langer analisa a obra de Du Bellay. Conforme o autor, a obra deste poeta se caracteriza por um uso particular do deíctico, por uma autoconsciência aplicada à redundância e pela escassez semântica. Esses recursos são aplicados em torno do "eu" do poeta, não para enriquecê-lo, mas no intuito de desnudá-lo, de reduzir sua consistência e seu poder de ação, até atingir o que parece ser seu fim poético e sua marca de "singularidade", o vazio ou o tédio. O poema 94 é um dos exemplos citados por Langer, no qual o poeta denuncia sentir-se sobrecarregado e esvaziado devido ao amor, que "retient le cours de mon ame ravie" (restringe a separação de minha alma arrebatada).

No capítulo seis, Langer discute a obra de Montaigne. Para o autor, o ensaísta é capaz de compreender e expressar em sua prosa aquilo que a poesia de Petrarca realiza, ou seja, seu efeito. Langer considera que Montaigne apresenta um senso de sublime, compreendido como algo intenso. Além disso, o autor menciona que sua prosa caracteriza-se pelos mesmos recursos que a poesia de Petrarca: o uso do deíctico como uma marca existencial, a redundância semântica e a intensificação da experiência. Langer exemplifica seus argumentos com uma das primeiras sentenças dos Ensaios: “Il t'avertit dèsl'entrée, que je ne m'y suis proposé aucune fin, que domestique et privée" (Que te adverte desde o começo que eu estabeleci a mim mesmo nenhum outro fim que não um privado e familiar). De acordo com Langer, a estética de Montaigne é orientada pela persistência e pelo impacto da singularidade, afastando-se da compreensão retórica da poesia. Nessa perspectiva, Langer menciona que a "singularidade" da obra de Montaigne seria justamente uma "linguagem lírica". 
Em suas conclusões, Langer sugere que tratar da poesia lírica através da retórica e da poética do período, como é de comum abordagem, seria uma aproximação limitada. Para o autor, o fenômeno da poesia lírica na pré-modernidade se estabelece de forma expansiva e complexa, sendo que algumas de suas características escapam às teorias poéticas e retóricas. Nessa acepção, Langer sugere uma reintrodução de elementos afetivos no processo de leitura. Ou seja, defende uma leitura simpática à obra, justamente por esta ser uma característica que o autor identifica na lírica. Para o autor, essa é uma das principais questões ao tratar-se de lírica, pois esse tipo de poesia se caracteriza por um acontecimento, como no caso de Petrarca, algo que indica uma "singularidade". Langer também ressalta que a subjetividade é um de seus mecanismos, não aquilo que a fundamenta. Nesse sentido, a lírica reaResenhade Lyric in the renaissance, de Ullrich Langer liza algo mais fundamental, uma reorientação da intenção poética, seu afastamento da universalidade dos mitos e seu movimento em direção a um gesto particular, como o de amor, que acontece em circunstâncias e entre indivíduos específicos e insubstituíveis. Langer ressalta que sua tese se direciona a um campo prático, não devendo ser compreendida como teoria ou ideologia. Desse modo, a mencionada "singularidade lírica" seria tratada como um efeito - que também anteciparia a noção moderna de poesia lírica.

Por fim, a obra de Langer se insere no âmbito das discussões teóricas acerca do gênero lírico. Um dos problemas frequentes ao campo seriam as dificuldades de definição do referido gênero, justamente pela imprecisão com que o termo "lírico" ou a ideia de poesia lírica foi tratada, desde a Antiguidade, até o período moderno. Nessa questão, "lírica" passou de uma composição oral e social, referente à Grécia arcaica, para um poema de expressão individual e subjetiva, na modernidade. Langer intenta resolver anacronicamente o problema da subjetividade, compreendendo-a como um mecanismo retórico. Principalmente pelo fato de que, na lírica arcaica, esta seria uma característica ausente. Nesse intuito, Langer se afasta da concepção de gênero para tentar compreender a lírica como um fenômeno, a partir de seu efeito, o que oferece perspectivas de estudo distintas ao pesquisador interessado no tema.

- Recebido em abril / 2017

- Aceite em junho / 2017 
